\title{
Effect of Vocal Fry on Voice and on Velopharyngeal Sphincter
}

\author{
Vanessa Santos Elias ${ }^{1}$ Carla Aparecida Cielo ${ }^{1}$ Geraldo Pereira Jotz ${ }^{2}$ Mara Keli Christmann ${ }^{1,3}$
}

${ }^{1}$ Departamento de Fonoaudiologia, Universidade Federal de Santa Maria, Santa Maria, Rio Grande do Sul, Brazil

2 Departamento de Ciências Morfológica, Universidade Federal do Rio Grande do Sul, Porto Alegre, Rio Grande do Sul, Brazil

3 Professor, Speech Therapy, Instituto Superior e Centro Educacional Luterano Bom Jesus (IELUSC), Joinville, SC, Brazil

\begin{abstract}
Address for correspondence Mara Keli Christmann, MSc, Departamento de Fonoaudiologia, Universidade Federal de Santa Maria, Av. Roraima n 1000 Cidade Universitária, Bairro Camobi Prédio 26-4 andar, Santa Maria, Rio Grande do Sul 97105-900, Brazil (e-mail: marakchristmann@gmail.com).
\end{abstract}

Int Arch Otorhinolaryngol 2016;20:156-162.

\begin{abstract}
Introduction It is known that the basal sound promotes shortening and adduction of the vocal folds and leaves the mucosa looser. However there are few studies that address the supralaryngeal physiological findings obtained using the technique.

Objective To check the effectiveness of using vocal fry on the voice and velopharingeal port closure of five adult subjects, whose cleft palate has been corrected with surgery. Methods Case study with five subjects who underwent otolaryngology examination by means of nasopharyngoscopy for imaging and measurement of the region of velopharyngeal port closure before and after using the vocal fry technique for three minutes. During the exam, the subjects sustained the isolated vowel /a:/ in their usual pitch and loudness. The emission of the vowel /a:/ was also used for perceptual analysis

Keywords

- voice

- cleft palate

- sound spectrography

- stomatognathic system abnormalities

- velopharyngeal sphincter and spectrographic evaluation of their voices.

Results Four subjects had an improvement in the region of velopharyngeal port closure; the results of the spectrographic evaluation were indicative of decreased hypernasality, and the results of the auditory-perceptual analysis suggested improved overall vocal quality, adequacy of loudness, decreased hypernasality, improvement of type of voice and decreased hoarseness.

Conclusion This study showed a positive effect of vocal fry on voice and greater velopharyngeal port closure.
\end{abstract}

\section{Introduction}

Anatomically, the velopharyngeal sphincter (VPS) correspond of the velum (soft palate), the lateral pharyngeal walls, and the posterior pharyngeal wall. It works as a valve that closes as a sphincter, separating the nasal and oral cavity, The action of the VPS and its structural integrity are very important to determine nasal resonance and intraoral pressure, which are necessary for the articulation of certain phonemes. ${ }^{1-7}$

Cleft palates are congenital malformations characterized by failure of fusion of the embryonic facial processes of the palate and may extend into the VPS region. To correct this deformity, surgery is the treatment of choice. However, surgical closure does not guarantee normal functioning of the structures involved, and individuals who underwent this surgery usually need speech rehabilitation as a result of communication difficulties. ${ }^{3,5,6,8-10}$

These difficulties relate to changes in voice resonance (hypernasality) and speech articulation (nasal substitution, compensatory articulation and lisping). ${ }^{1-5,11}$ Hypernasality shows very strong negative social connotation and, therefore, it represents a stigma for people with a cleft palate. ${ }^{1,3,6,9-13}$

Speech rehabilitation is accomplished through guidelines and mobilization techniques for the structures of the received

May 4, 2015

accepted after revision

September 22, 2015

published online

December 15, 2015
DOI http://dx.doi.org/

10.1055/s-0035-1569144. ISSN 1809-9777.
Copyright $\odot 2016$ by Thieme Publicações License terms

Ltda, Rio de Janeiro, Brazil

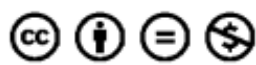


stomatognathic system to improve its functions, compensating for anatomical changes. $1,2,5,10,12$

One of the techniques that can be used is vocal fry, produced primarily by the contraction of the thyroarytenoid muscle (TA), which at the laryngeal level, shortens and adducts the vocal folds, loosens the mucous membrane, makes the free edge more rounded and lowers the vertical level of the vocal folds. ${ }^{14-16}$ During emission, the soft palate is tightly close to the posterior pharyngeal wall, which theoretically could lead to a reduction in hypernasality after the vocal fry technique is used. ${ }^{2,3,15}$

Nevertheless, there are few studies on this technique with patients undergoing surgical repair of cleft palate. Additionally, in the studies on the vocal fry technique, few authors reported supralaryngeal physiological findings when using the technique. ${ }^{2,3,15,16}$

Speech therapists should be familiar with vocal anatomy and physiology, as well as the physiology underlying the therapeutic techniques so that they can be properly employed in several clinical cases. ${ }^{15-17}$

These aspects motivated this research, whose objective is to verify the effect of the vocal fry technique on the voice and VPS closure of five adult subjects suffering from repaired post-foramen cleft palate.

\section{Methods}

\section{Description of the Research}

This research is descriptive, and the case study method was used.

\section{Ethical Aspects}

This study was approved by the Research Ethics Committee of the university where it was conducted, under protocol number 006-04. All ethical issues arising from conducting the experiments and assessments with humans met the demands of the standard 466/2012 of the National Committee of Ethics in Research (CONEP). An Informed Consent Form (ICF) was signed by the subjects, and an Institutional Authorization Agreement (IAA) was forwarded to a reference speech pathology center that cares for cleft palate patients.

\section{Research Subjects}

The following subject inclusion criteria were established to choose the cases to be studied: surgically repaired postforamen cleft palate ${ }^{13}$; age range between 18 and 40 years, thus avoiding the influence of possible effects of voice change or presbyphonia; ability to perform vocal fry. ${ }^{2,3}$ Exclusion criteria were: hearing loss, ${ }^{11,13}$ since it is known that hearing is determinant in the quality and control of vocal production, and lack of auditory feedback or distortion could compromise the auditory perception of hypernasality and production of vocal fry, which may lead subjects to produce it with unnecessary effort and muscle tension; having undergone prior speech therapy, so as to avoid the fact that adequate muscle compensations may have been used to stimulate VPS closure. $^{2,3}$

Records of all patients from the database of an institution of reference that cares for cleft palate patients were analyzed to verify the inclusion criteria for the type of cleft palate, the respective surgical repair and age, according to the criteria described above.

This step resulted in 14 subjects, five males and nine females who were invited to participate in the research. An interview was conducted to collect identification data and indepth information on their history of surgeries and treatments. The otolaryngologist of the speech pathology service requested that they undergo a hearing assessment. Access to such data resulted in the exclusion of nine volunteers. The study group was, thus, composed of five subjects, four men and one woman, aged between 20 and 26 years.

\section{Data Collection}

The subjects attended an oral explanation session on the importance of the present study and the treatment technique to be used. On that occasion, they were taught how to perform the vocal fry technique while being assisted by four speech therapists. $^{2,3}$

An ENT evaluation was performed in a doctor's office, by means of nasopharyngoscopy $5,6,11,13$; the velopharyngeal function was examined. For this evaluation, the following equipment was used: VHS tape for videotaping, a Semp Toshiba Lumina Line 14-inch TV set, a Sony SLV - 66 BR 4head Video Cassette Recorder, a Welch Allyn RL -100 Rhinolaryngoscope, a Kom Lux Fibras Ópticas - HL2250 Cold Light Source, and technology to save video-tape images into a $c d$ room, for further image analysis with Virtual Dub video editing software and Pinacle PCTV video capture driver. In all patients the fiberendoscopy was introduced by the right nostril being positioned $\sim 0.5 \mathrm{~cm}$ above the arytenoids positioned in the center of the vocal folds, with anteroposterior view of the glottis.

Nasopharyngoscopy was conducted in two stages, while the subjects were sitting down. The first stage occurred when the subjects produced the emission of the vowel / a: / in their regular pitch and loudness for at least three seconds prior to performing the technique $e^{2,8,11,17-19}$ and the second stage after using the technique, under the same pre-technical conditions. $^{6,17,18}$

During the emission of the vowel /a:/, the voices were recorded using a $M Z R-70$ minidisc recorder, connected to a professional MP-68 unidirectional microphone with a $L e$ Son ${ }^{\circledR}$ electret condenser. The microphone was placed at a distance of $5 \mathrm{~cm}$ and $90^{\circ}$ in front of the mouth of each subject. $3,17,18,20$

To perform the technique, the subjects were asked to produce pulse register phonation of vowel /a/ continuously and effortlessly. This emission was held for three minutes, timed by a speech therapist. ${ }^{3,17,18}$

\section{Data Analysis}

The images selected from the nasopharyngoscopy, before and after the technique, were scanned and pasted on Power Point slides to delimit the region of VPS closure. The software Vector Works (usually used in architecture to calculate a given region automatically) was used to calculate the subjects' VPS closure regions. $^{2}$ 


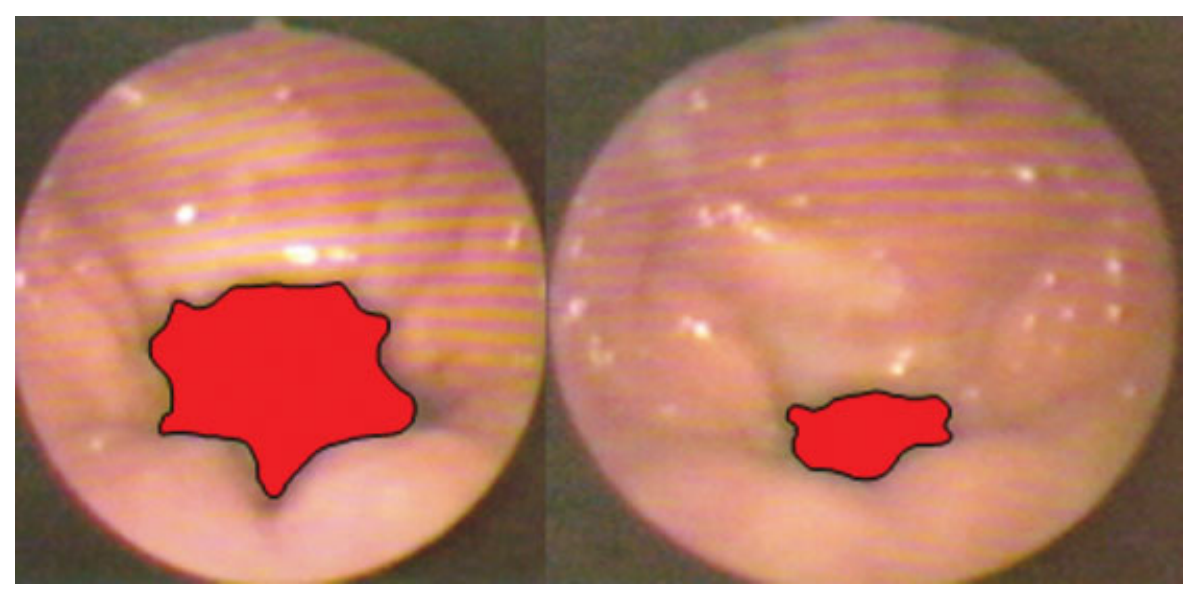

Fig. 1 VPS closure in modal register before and after vocal fry in one of the male subjects (increase in VPS closure $=10.76 \mathrm{~cm}^{2}$ )

Each image was scaled arbitrarily at $12.5 \times 10 \mathrm{~cm}^{2}$ for calculating the VPS closure region, by comparing the images prior to and after vocal fry and measure the increase in VPS closure in $\mathrm{cm}^{2}$. This does not mean that the anatomy of the subjects showed these measures, but rather that the images were enlarged to enhance visualization and calculation of increase in VPS closure region. ${ }^{2}$

The VPS closure regions were delimited before and after vocal fry was performed, considering as boundaries within the range of proximity to the soft palate, lateral and posterior pharyngeal walls, ${ }^{2}$ based on other studies that performed measurements from images of videolaryngoscopy or nasopharyngoscopy examinations ${ }^{2,21}$ (-Fig. 1).

Auditory-perceptual and acoustic evaluation of voice was performed, based on the emission of the vowel /a:/. The auditory-perceptual evaluation was performed individually by four experienced speech therapists that were not authors of the present study. The answers in common or prevalent among the ratings of the judges were the ones taken into account. Each speech therapist was blinded to the objectives of this research, the length of each emission and the evaluations of the other judges. ${ }^{17,18}$

The parameters evaluated were: type of voice (hoarse, rough, breathy, pressed, normal, or other), focus of vertical resonance (balanced, high/hypernasal, pharyngeal, laryngeal or laryngopharyngeal), pitch (adequate, high, or low) and loudness (appropriate, increased or decreased). ${ }^{20}$ Degrees of severity were also assigned to each item, ranging from: mild, moderate, severe and extreme. ${ }^{17,18}$

The acoustic analysis was performed using the software Real Time Spectrogram (RTS) by Kay Pentax ${ }^{\circledR}$ installed on an appropriate computer with all the specifications of the manufacturer in broadband filter at 100 points $(646 \mathrm{~Hz})$ and narrowband filter at 1024 points $(63,09 \mathrm{~Hz})$, with a sampling rate of $11 \mathrm{kHz}$ and 16 bits. Assessments were made by two speech therapists/judges; for the purpose of results, the data in common between the ratings of the judges ${ }^{3,17}$ were taken into account.

The items assessed through the broadband spectrograph and the narrowband spectrograph were the same, namely: intensity of formant transitions (F), of high frequencies and of the whole vocal spectrogram; antiresonance/damping immediately above the 1st formant (F1) and throughout the vocal spectrum. Formants were defined, and the third and fourth formants (F3 and F4) were also analyzed for their appearance, disappearance, or unchanged the definition of harmonics, the presence of noise, and formant transition regularity. $^{3}$

The assessment of severity of the transitions (of formants, of high frequencies and of the whole spectrogram), the degree of darkening of the transitions was evaluated; it could range from black (high intensity) to light gray (low intensity), ${ }^{22}$ and it was ranked as increase (improvement), decrease (worsening) or no change. Anti-resonance/damping (above F1 and throughout the whole vocal spectrum) refers to the sound muffling resulting from voice softening in the nasal cavity, which may be related to hypernasality and could be ranked as increase (worsened), decrease (improved) or no change. The definition of formants and harmonics were evaluated according to their visibility, demarcation and symmetry, and they could be considered as more defined (improvement), less defined (worsening) or no change. Noise is seen in the spectrogram as a shaded or dotted image, depending on the degree of darkening of the shading/dithering and it could be classified as reduced (improvement), increased (worsening) or no change. The regularity of the tracing is related to its continuity and stability, and it could be classified as more regular (improvement), less regular (worsening) or no change. ${ }^{3,22}$

After the evaluations, the results were analyzed descriptively.

\section{Results}

- Table 1 show the results of the auditory-perceptual evaluation of the group of subjects.

- Table 2 shows the results of the VPS closure region before and after vocal fry.

- Table 3 shows the results of the broadband and narrowband spectrograms. 


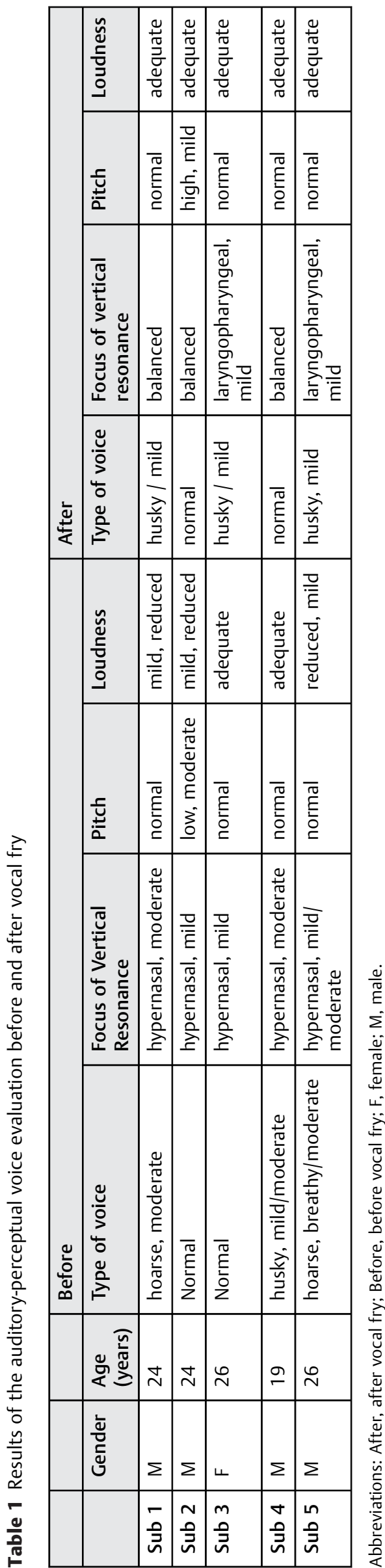

\section{Discussion}

A case study with two female subjects who had a laryngeal diagnosis of triangular chinks and performed vocal fry into three sets of 15 repetitions, compared laryngeal examination and perceptual voice analysis before and after using technique. The results showed that vocal fry provided improved glottal closure and improved vibration amplitude of the mucosa of the vocal folds, but type of voice was worsened. ${ }^{17}$ The authors justified the worsening of voice quality by stating that the subjects may have had difficulty in reversing laryngeal adjustments they had adopted for vocal fry when resuming their usual voice register (modal register) ${ }^{14,17}$.

The results of the present research, however, contradict the results of the latter study as regards type of voice, because there were improvements in four of the five participating subjects (-Table 1 ). This discrepancy may be due to the fact that the technique was used at different times in the two studies. The literature shows that the TA muscle predominantly has type II muscle fibers, which have fast twitch but are highly fatigable. Thus, assuming that vocal fry requires excessive effort from TA muscle fibers, performing the technique for long periods may cause fatigue. ${ }^{16,18,20}$ It is still unclear in the literature which time length or exact number of repetitions can lead to voice improvement; nevertheless, in the present study, length of execution did not exceed three minutes, and there was an improvement of voice type.

Another case study corroborates this assertion; the vocal fry technique was used (three sets of 15 repetitions) in five women without laryngeal disorders. Two women showed no changes for type of voice, while type of voice worsened for two of them, and only one showed improvement for type of voice. Also regarding quality of vocal emission, it was found that the vocal fry technique promoted increased instability, with frequency breaks and ends of vocal fry emissions in two subjects; there was improvement of these aspects in only one of the subjects. ${ }^{18}$

Still, the auditory-perceptual vocal analysis in this study showed a reduction of hypernasality in all subjects ( - Table 1), due to a larger VPS closure region in four subjects (-Table 2) after vocal fry phonation. The literature points to the importance of measuring this aspect through direct instrumental evaluation (nasoendoscopy) and clinical evaluation (auditory-perceptual assessment), ${ }^{4,13}$ as was done in the present study. There is a clear association between the results of these two assessments. ${ }^{19}$

There was reduction of hypernasality, which is in agreement with the literature, because vocal fry phonation leads to greater VPS closure since vocal production requires synchronization between the closing of the valves (VPS and vocal folds); there is a clear physiological interrelationship between larynx and soft palate. ${ }^{15}$ Thus, because vocal fry increases glottal adduction, ${ }^{14}$ it also increases the nasopharyngeal constriction and raises the PVS region. ${ }^{2,15}$

A study that compared the type of VPS closure during the emission of the vowel /a/ and during vocal fry phonation found that the type of closure was maintained in most patients during the two situations, and there were changes 
Table 2 VPS closure region before and after vocal fry

\begin{tabular}{|l|l|l|l|l|l|}
\hline & Gender & Age (years) & \multicolumn{2}{l|}{ Closure region } \\
\cline { 4 - 7 } & & & Before $\left(\mathrm{cm}^{2}\right)$ & After $\left(\mathrm{cm}^{2}\right)$ & Increase $\left(\mathrm{cm}^{2}\right)$ \\
\hline Sub 1 & M & 24 & 7.79 & 2.48 & 5.31 \\
\hline Sub 2 & M & 24 & 3.25 & 3.17 & 0.08 \\
\hline Sub 3 & F & 26 & 5.83 & 25.88 & -20.05 \\
\hline Sub 4 & M & 19 & 14.25 & 3.49 & 10.76 \\
\hline Sub 5 & M & 26 & 1.23 & 0.39 & 0.84 \\
\hline
\end{tabular}

Abbreviations: After, after vocal fry; Before, before vocal fry; F, female; Increase, increase in VPS closure region; M, male.

Table 3 Results of broadband and narrowband spectrograms

\begin{tabular}{|c|c|c|c|c|c|}
\hline & Sub 1 & Sub 2 & Sub 3 & Sub 4 & Sub 5 \\
\hline Gender & M & M & $\mathrm{F}$ & M & M \\
\hline Age (years) & 24 & 24 & 26 & 19 & 26 \\
\hline Tracing intensity of $\mathrm{F}$ & 1 & 1 & W & 1 & I \\
\hline Tracing intensity of high frequencies & $\mathrm{I}$ & $\mathrm{N} / \mathrm{C}$ & W & 1 & I \\
\hline Tracing intensity in the whole spectrum & I & $\mathrm{N} / \mathrm{C}$ & W & 1 & I \\
\hline Antiresonance/damping immediately above F1 & I & 1 & W & 1 & I \\
\hline $\begin{array}{l}\text { Antiresonance/damping in the whole } \\
\text { vocal spectrum }\end{array}$ & 1 & 1 & W & 1 & 1 \\
\hline Definition of $F$ & $\mathrm{~N} / \mathrm{C}$ & 1 & $\mathrm{~N} / \mathrm{C}$ & 1 & I \\
\hline $\mathrm{F} 3$ and $\mathrm{F} 4$ & $\begin{array}{l}\text { Appearance of } \\
\text { F3 and F4 }\end{array}$ & $\mathrm{N} / \mathrm{C}$ & $\begin{array}{l}\text { Disappearance } \\
\text { of F3 }\end{array}$ & $\begin{array}{l}\text { Appearance } \\
\text { of F3 and F4 }\end{array}$ & $\begin{array}{l}\text { Disappearance } \\
\text { of F3 }\end{array}$ \\
\hline Definition of harmonics & $\mathrm{N} / \mathrm{C}$ & $\mathrm{N} / \mathrm{C}$ & $\mathrm{N} / \mathrm{C}$ & I & I \\
\hline Presence of noise & $\mathrm{N} / \mathrm{C}$ & $\mathrm{N} / \mathrm{C}$ & $\mathrm{N} / \mathrm{C}$ & $\mathrm{N} / \mathrm{C}$ & $\mathrm{N} / \mathrm{C}$ \\
\hline Regularity of tracing & 1 & $\mathrm{~N} / \mathrm{C}$ & $\mathrm{N} / \mathrm{C}$ & $\mathrm{N} / \mathrm{C}$ & I \\
\hline
\end{tabular}

Abbreviations: F, female; F, formant; I = improvement; $M$, male; N/C, no change; $W$, worsening.

in the degree of movement of the structures involved. That study also observed that during vocal fry phonation, movement of the posterior pharyngeal wall was greater and more stable, and the presence of the Passavant fold was also evident, ${ }^{2}$ suggesting that during vocal fry, these structures offset VPS closure in patients with reduced soft palate movement.

In another case report, a 25-year-old male patient with repaired post-foramen cleft palate showed mild hypernasality in an auditory-perceptual voice analysis and incomplete velopharyngeal closure in the nasoendoscopy examination. He showed medialization of the sidewalls and greater anteriorization of the posterior pharyngeal wall, as well as elevation of the soft palate and uvula, causing total VPS closure during vocal fry phonation. ${ }^{23}$

Unfortunately, there were not found international studies examining the effect of basal sound on the VPS.

The present study supports these findings and shows that even the greatest VPS closure continued during emission of the vowel /a/ in modal register, immediately after vocal fry. ${ }^{15}$ Further research should be conducted with longitudinal studies to check if this result continues for long periods after vocal fry exercises.

The auditory-perceptual voice analysis showed that the only male subject who had moderately high pitch improved this aspect after vocal fry exercises, and the three patients who had slightly lower loudness began to show adequate loudness after performing the technique (-Table $\mathbf{1}$ ). These findings are consistent with a case study with a subject whose pitch lowered after vocal fry. ${ }^{18}$ Increased loudness can be justified by the physiology of higher glottal closure during vocal fry phonation, when there is an increase in subglottic pressure, thus directly affecting sound pressure level (SPL) and, for that matter, loudness. ${ }^{3,15,17,18}$ It is also possible that the increase in loudness, directly correlated with the sound pressure level may have also contributed to the increase in VPS closure and the reduction of hypernasality, since a study, although in normal subjects, showed improvement closure of the VPS during speech at high sound pressure level. ${ }^{7}$

In the present study, pitch may have been lowered as a result of laryngeal adjustments during vocal fry, as its emission occurs in lower frequencies of the vocal range and both 
source and filter adjustments may have remained after the technique, leading to changes in pitch. ${ }^{14,16}$ However, pitch is the auditory-perceptual correlate of fo, and it is affected by the vocal tract, but there is no linear relationship between the two aspects. ${ }^{18}$ Thus, one might think that the reduction of hypernasality in the same subject may also have contributed to changing his pitch. ${ }^{16}$

The literature shows that the most common spectrographic characteristics of hypernasality are: reduced intensity of $F$ (mainly F1 and high frequencies); reduced intensity of high frequency harmonics, and presence of antiresonance (especially above F1). ${ }^{24}$ Regarding the spectrographic voice analysis, the aspects intensity of transitions of $F$, of high frequencies and of the vocal spectrum; anti-resonance/damping immediately above F1 and throughout the vocal spectrum; definition of F; presence of F3 and F4; definition of harmonics and regularity of transitions improved in four out of the five subjects (-Table $\mathbf{3}$ ).

A spectrographic study compared analyses before and during vocal fry execises in men with repaired post-foramen cleft palate. It was observed that the intensity of $\mathrm{F}$, of high frequencies and the whole vocal spectrogram, both in BBS and NBS, remained the same or decreased during vocal fry phonation; they were low in most cases, which is expected because vocal fry is characterized by low sound pressure, except for one subject in BBS, who showed increased intensity of F1, and another subject in NBS, who showed increased intensity in the whole spectrogram during vocal fry phonation. Furthermore, damping increased during vocal fry. ${ }^{3}$

In this study, two subjects began to show laryngopharyngeal resonance after using the technique, which suggests increased supraglottic tension during phonation, possibly due to the lowering of the larynx and shortening of the vocal folds, which commonly occur with the use of vocal fry, as well as subjects' particular muscle adjustments, because they had repaired cleft palate. The effect of resonance depends on how the subject modifies the laryngeal signal when it passes through the laryngeal supraglottic cavities, depending on the adjustments made for the shape and tension of the vocal tract. This finding does not agree with the literature, which states that vocal fry balances resonance, increasing the oral resonance and reducing hipernasality. ${ }^{18}$

Only one out of the five study patients, the female subject, who had no improvement in any aspect of the spectrographic analysis, showed an increase in the gap region and, contradictorily, improved hypernasality in the auditory-perceptual voice evaluation. The reasons for this worsened condition were not clear, but perhaps a small gap in the VPS region may produce greater air turbulence and more hypernasality than a larger gap, because there is no direct linearity between the gap size and the noise level effectively found on the voice. ${ }^{5}$

In an investigation, 14 children who had gap in the VPS region, due to the repaired cleft lip and palate, were compared with 14 normal subjects, through acoustic voice analysis. The children in the study group had higher values of jitter and shimmer than children in the control group, but when the children in the study group were compared with each other, by the gap size difference, only the shimmer was higher in those with moderate gap, when compared with those with mild gap ${ }^{13}$. Future research may clarify these issues.

It is noteworthy that, statistical generalizations of the results cannot be made, because it is a case study, this work contributes as a step toward investigating the effect of vocal fry on the VPS region of adults with surgically repaired cleft palate.

It is evident that even patients undergoing timely surgical treatments remain with hypernasality; thus, speech therapy $^{12}$ is necessary and important. For this reason, future research should focus on the approach used in this study while considering gender, age, time variations of the technique, and other pathologies.

\section{Conclusion}

The vocal fry technique improved the VPS closure region. In most subjects, the auditory-perceptual and spectrographic voice analysis were indicative of decreased hypernasality, decreased hoarseness and adequacy of loudness.

\author{
Conflicts of Interest \\ None.

\section{Research Funding Agencies} \\ CAPES/FAPERGS.
}

\section{References}

1 Lima MRF, Leal FB, Araújo SVS, Matos EF, Ninno CQMSD, Britto ATBO. Intensive speech therapy in patients operated for cleft lip and palate: case report. Rev Soc Bras Fonoaudiol 2007; $12: 240-246$

2 Conterno G, Cielo CA, Elias VS. Fissura palatina reparada: fechamento velofaríngeo antes e durante o som basal. Braz J Otorhinolaryngol 2010;76(2):185-192

3 Conterno G, Cielo CA, Elias VS. Características vocais acústicas do som basal em homens com fissura pós-forame reparada. Rev CEFAC. 2011;13:171-181

4 Paniagua LM, Signorini AV, Costa SS, Collares MVM, Dornelles S. Velopharyngeal dysfunction: a systematic review of major instrumental and auditory-perceptual assessments. Int Arch Otorhinolaryngol 2013;17(3):251-256

5 Wagreich P. The role of the speech-language pathologist in maximizing the results of instrumental assessment of velopharyngeal function. Plast Surg Nurs 2014;34(2):72-74

6 Kummer AW. Speech evaluation for patients with cleft palate. Clin Plast Surg 2014;41(2):241-251

7 Jiang M, Yang Z, Feng B, You M, Wang H. The effect of sound intensity on velopharyngeal function in normal individuals. J Voice 2015;29(1):44-52

8 Sedano R, Rodríguez JG, Morovic CG, Pizarro O, Alarcón J, Salgado E. Fisura labial y/o palatina en un centro de derivación de malformaciones congénitas. Rev Chil Ultrason 2007;10:4-10

9 Mishima K, Nakano H, Matsumura T, Moritani N, Iida S, Ueyama Y. Nonlinear dynamic analysis of vowels in cleft palate children with or without hypernasality. Int J Otolaryngol 2012;1:1-4

10 Bispo NHM, Whitaker ME, Aferri HC, Neves JDA, Dutka JdeC, Pegoraro-Krook MI. Speech therapy for compensatory articulations and velopharyngeal function: a case report. J Appl Oral Sci 2011;19(6):679-684 
11 Netto BCA, Cervante O. Comparative study among cleft patients with velopharyngeal insufficiency treated with speech therapy and pharyngoplasty. Rev Bras Cir Plást. 2011;26:631-638

12 Priester GH, Goorhuis-Brouwer SM. Speech and language development in toddlers with and without cleft palate. Int J Pediatr Otorhinolaryngol 2008;72(6):801-806

13 Villafuerte-Gonzalez R, Valadez-Jimenez VM, Hernandez-Lopez X, Ysunza PA. Acoustic analysis of voice in children with cleft palate and velopharyngeal insufficiency. Int J Pediatr Otorhinolaryngol 2015;79(7):1073-1076

14 Wolk L, Abdelli-Beruh NB, Slavin D. Habitual use of vocal fry in young adult female speakers. J Voice 2012;26(3):e111-e116

15 Cielo CA, Elias VS, Christmann MK, Conterno G. Evidencia cientifica sobre o som basal em pacientes com fissura palatina pós forame reparada cirurgicamente. In: Pró-fono. Terapia fooaudiológica baseada em evidências. 2013, p. 441-60.

16 Cielo CA, Brum DM, Bolzan GP, Finger LS. Evidencia científica sobre a técnica de som basal. In: Pró-fono. Terapia fooaudiológica baseada em evidências. 2013, p. 371-88.

17 Bolzan GP, Cielo CA, Brum DM. Efeitos do som basal em fendas glóticas. Rev CEFAC 2008;10(2):218-225

18 Brum DM, Cielo CA, Finger LS, Manfrin JA. Considerações sobre modificações vocais e laríngeas ocasionadas pelo som basal em mulheres sem queixa vocal. Rev Soc Bras Fonoaudiol. 2010;15(2): 282-288

19 Paniagua LM, Signorini AV, Costa SS, Collares MVM, Dornelles S. Comparison of videonasoendoscopy and auditory-perceptual evaluation of speech in individuals with cleft lip/palate. Int Arch Otorhinolaryngol 2013;17(3):265-273

20 Behlau M (Org.) Voz: o livro do especialista. Rio de Janeiro: Revinter; 2008

21 Carrara E. Análise comparativa da configuração laríngea, perceptual auditiva e espectrográfica acústica da qualidade vocal pré e pós emissão vocal em registro basal. [Monografia]. São Paulo (SP): Universidade Federal de São Paulo; 1991

22 Valentim AF, Côrtes NG, Gama ACC. Análise espectrográfica da voz: efeito do treinamento visual na confiabilidade da avaliação. Rev Soc Bras Fonoaudiol 2010;15(3):335-342

23 Elias VS, Cielo CA, Knak IS, Faller GJ. Efeito do som basal em um caso de deficiência velofaríngea leve. In: XII Congresso Brasileiro de Fonoaudiologia, II Congresso Sul Brasileiro de Fonoaudiologia, 2004, Foz do Iguaçu. Anais. Foz do Iguaçu: Sociedade Brasileira de Fonoaudiologia, 2004

24 Souza MCQ. Características espectrais da nasalidade [dissertação]. São Carlos(SP): Universidade de São Paulo: São Carlos. Programa de Pós-Graduação Interunidades em Bioengenharia; 2003 